\title{
Asynchronizing with the Framework Reflections on the process of creating an asynchronous library assignment for a first-year writing class
}

A

s many of yours surely have, my institution, the University of Illinois-Chicago (UIC), moved at great speed to adapt to the need for online instruction this fall. This has proved a challenge for library instruction, to put it mildly. Our library instruction has almost exclusively been in-person, on-site, and live, and the switch to online and hybrid course delivery has made all of those aspects difficult, especially when it comes to courses offered asynchronously, where students engage with course content at different points in time within a given timeframe.

In my previous experience teaching and designing asynchronous college courses, I found that a shift in approach was necessary to deliver satisfying results similar to those achievable in the traditional classroom environment. Students can learn effectively if designed with deliberation and with a sense of limitations and opportunities presented in an asynchronous classroom.

To that end, I developed a technique of library instruction for asynchronous firstyear writing courses that seeks to achieve several goals:

- to provide adequate library instruction to allow students within the course to complete their assignments;

- to align with elements of the ACRL Framework for Information Literacy for
Higher Education previously identified as suitable for this course, so as not to leave a cohort of students less prepared for later research;

- to allow assessment of work without exceeding the amount of time normally spent on an individual class;

- to align with the goal of asynchronous education, allowing students to manage their own time and not requiring a scheduled appointment; and

- no expensive tools or software for me or for students.

With those goals in mind, I developed an online assignment form, in a rough draft state before tailoring for individual instructors. ${ }^{1}$ This assignment achieves the goals laid out above and provides a model through which others might produce similar tools for asynchronous instruction at their own institutions. Below, I will discuss the process of creation, including the background of first-year library instruction at my institution, the process of design, and the methods of making the final product.

B. Grantham Aldred is assistant professor and reference librarian at the University of Illinois-Chicago, email: baldred2@uic.edu

(C) 2020 B. Grantham Aldred 
Overall, my goal is to provide a model of what an asynchronous library session might look like at an institution where live instruction is the norm.

\section{Background}

At UIC, we have a robust history of firstyear library instruction, coordinating with our first-year writing program to provide library sessions for all sections of the English 160 and English 161 courses and Introduction to College Writing I and II. Nearly all students take English 161 and are required to make use of scholarly sources in their assignments, so it is our chance to teach all students the basics of information literacy.

Normally, the Research Services and Resources department offers one to two sessions for each class, one session for class periods in 75-minute time slots, two for classes in 50-minute time slots, which are scheduled by individual instructors.

In previous years, the department has coordinated internally to develop instruction based on the ACRL Framework, working to ensure that students get a consistent and useful experience. Our focus for English 161 has been on the following elements of the Framework and dispositions/ knowledge practices.

\section{Scholarship as Conversation}

- seek out knowledge practices in their research area (disposition),

- recognize that scholarly conversations take place in various venues (disposition), and

- recognize that a given scholarly work may not represent the only-or even the majority-perspective on one issue (knowledge practice).

\section{Searching as Strategic Exploration}

- recognize that first attempts at searching do not always produce adequate results (disposition)

While the department coordinated on overall goals, individual librarian instruc- tors designed their own specific sessions, and I focused mine on a method called "How to Search Like a Librarian," which served as the basis for my asynchronous assignment.

\section{Normal class}

In designing my normal instruction protocol, I focused on breaking the basic library research process down into discrete achievable and assessable tasks that could be taught in order. In class, I would teach one part of the search process, then let the students try it for about 5 minutes, as I walked through the classroom and got them past any stumbling blocks. I then moved on to the next part of the search process. I used a small paper form for students to keep track of their own process.

\section{Discrete achievable tasks}

- finding the library website and doing a basic search,

- breaking a search topic into keywords,

- finding a library database and doing a search there using Boolean term AND,

- using Boolean term OR to expand search results with alternate keywords,

- using database filters to reduce search results,

- getting access to articles using library tools(Find it @ UIC, Interlibrary Loan),

- keeping track of results using permalinks and citation management software, and

- how to access library help after class.

By the end of a session, students can find articles and access books, understand that there are different databases for different subjects, and use library search tools to improve search results. I use a running metric of the number of search results to demonstrate to students the effects of their choices, showing how OR gets more potentially good results and filters eliminate irrelevant results. 


\section{Abnormal needs}

Due to the COVID-19 crisis, classes at UIC moved to a hybrid model: some classes doing partial in-person instruction and others moved entirely online with a mix of synchronous and asynchronous instruction as decided by departments and instructors. While a synchronous online class could cover similar material to an in-person synchronous class, moving to asynchronous required changes. There were a number of things I could still do roughly the same, but others were no longer possible.

A number of aspects required minimal adaptation. Students still have access to all online library resources as we use proxy authentication to allow off-campus users. I can still provide lectures and demonstrations, though I had to use different methods of delivery to pre-record videos rather than lecture directly.

The things that require significant change are more extensive. I cannot do demonstrations using student-supplied examples. I can't walk around the room and offer live consultations on student topics and research practices. I can't monitor student engagement by looking at their monitors. I can't vary the content of examples, as the time commitment for recording lectures is significant enough to make creating more than one version prohibitive.

Based on these changes, I set out to find new methods to achieve the same goals.

\section{Design process}

In designing this session, I had a number of goals. First, I wanted to design something that allowed assessment. Having something the students submit as part of the instruction session achieved several goals. Students could be held accountable for participation if the instructor wanted to make it a class assignment. It allowed follow-up communication, as I could collect their emails as part of their submission and provide direct feedback to them on their search process, similar to the help that I provide in a live session. To that end, I designed an interactive form assignment using Google Forms through UIC's Google Suite. While this has a cost in the form of my time, when compared with design time and class time, it is comparable per class. While the university account had limitations in terms of only allowing UIC users to submit responses, even a free google account could allow for email address collection.

Second, I wanted to break the lesson into component parts. In the live session, I alternate between lecture/demonstration and student participation, and I find that effective in maintaining student interest and allowing easy retention of information between demonstration and student experimentation. This lined up well with best practices for video instruction, as I was able to break the lessons into three-minute chunks, so that they were more engaging. I broke it out into multiple pages, to not seem too intimidating and to make clear that the blank in the form was connected to the video on the same page. Literally, I want to make sure we were all on the same page. Additionally, in asynchronous instruction, a student may be interrupted while doing the assignment, and multiple segments made it easier to resume work.

Third, I wanted it to not cost money to make. Google Forms was available at the university and, while I could have used some of the university's video recording options, I chose to use Open Broadcaster Software $^{2}$ for video, which allowed easy recording using home equipment. These videos could be uploaded to YouTube, which allowed for students to repeat lessons as necessary and for the easy creation of subtitles for accessibility purposes using YouTube's own subtitle editing tools.

Most importantly, I wanted to make sure there was a degree of interactivity. Asynchronous instruction relies on interactivity to maintain engagement. Without some sense that their responses were part of the process, students may 
engage with content passively and reduce retention.

Based on this, I scripted short videos, recorded them, and assembled them into the rough draft form. The video was then submitted to peer instructors to get feedback and then was edited accordingly, clarifying certain examples. ${ }^{3}$

The instructional design of the assignment deliberately tried to highlight several of the dispositions and practices from the Framework that were part of the normal class session. Related to Scholarship as Conversation, students were required to search in multiple databases, highlighting how "scholarly conversations take place in various venues." Students had to identify multiple sources, teaching them to "recognize that a given scholarly work may not represent the only...perspective on one issue." Related to Searching as Strategic Exploration, students were shown how to revise keywords for searching and use database filters to improve search results, tied to the disposition "recognize that first attempts at searching do not always produce adequate results."

\section{Preliminary reflections on results}

The preliminary results of this asynchronous option have been generally positive. Multiple instructors opted to go with the asynchronous library instruction session and have given positive feedback on the results with their students. Some more detailed arrangements were necessary for scheduling to make sure that students got timely feedback and helpful tips. The students themselves have responded very positively to feedback, and the department has seen a rise in research consultations from first-year students.

While the time commitment for providing feedback has increased, all students now get individual librarian attention in a way that guarantees contact. Additionally, the process of student feedback has allowed the highlighting of a further disposition from the Framework, "seek out knowledge practices in their research area." As student topics are submitted with the assignment, I have been able to point them to specialized resources related to their topic, including subject databases and specific data resources.

\section{Conclusions}

Overall, this is a quick demonstration, a model for what an asynchronous online instruction session lined up with the ACRL Framework might look like. With a limited timeline, my focus was on modeling what might be achievable in such a format. Student time is valuable, and asynchronous instruction has many benefits for student equity, but it's outside most librarian's experience. Having taught online in both synchronous and asynchronous contexts and designed and delivered asynchronous courses, I wanted to show that this is possible without giving up alignment with the ACRL Framework. This similar model could be used for a flipped classroom- style assignment, depending on instructor preferences.

Asynchronous library sessions do not mean leaving a cohort behind. The entire purpose of the ACRL Framework is to recognize the shared educational goals of information literacy and to allow us as librarians to adapt them to our variety of contexts. I hope this sample gives food for thought and helps as you consider plans for online library instruction during the COVID-19 crisis and beyond.

\section{Notes}

1. Online assignment form, https://forms. gle/iwXWcr63i5AgutoLA.

2. Broadcaster Software, https://obsproject. $\mathrm{com} /$.

3. The version shared at https://forms.gle /iwXWcv63i5AgutoLA is a rough draft, put together to help instructors decide whether they wanted synchronous or asynchronous sessions for their classes, to help them understand what asynchronous library instruction might involve, as this is as new to them as it is to us. $\boldsymbol{n}$ 